\title{
Tobacco and betel quid in development of oral
}

\section{cancer}

\begin{abstract}
Oral cancer is a public health problem in many parts of the world, representing the sixth most common malignant neoplasm. Oral cancer epidemiologically registers over 300000 new cases of oral cancer annually; two thirds of these cases occur in developing countries. The incidence of oral cancers among men is highest in northern India, a few areas of central and Eastern Europe, and Latin America. In Asian countries the high incidence rates were reported from developing nations like India, Pakistan, Bangladesh and Taiwan. Oral cancers displayed the worst survival rates in Latin America, India and Yemen. Some countries share specific risk factors namely heavy tobacco smoking, alcohol consumption, chewing of betel-quid, gutka, Zarda, Kharra, snuff and Khat. In addition, other specific risk factors are viral infection (HPV), poor oral hygiene and high intake of charcoal-grilled red meat and mate. Recommendation: Urgent public health measures are needed to reduce the incidence and mortality of oral cancer.
\end{abstract}

Keywords: oral cancer, risk factors, tobacco, betel quid
Volume 7 Issue I - 2017

\author{
Gamal Abdul Hamid, ${ }^{1,2}$ Nasser Baom² \\ National Oncology Center, Yemen \\ ${ }^{2}$ Faculty of Medicine, University of Aden, Yamen
}

Correspondence: Gamal Abdul Hamid, National Oncology Center, Aden University, Aden, Yemen,

Email drgama12000@yahoo.com

Received: September 25, 2016 | Published: January 09, 2017

\section{Introduction}

Cancer is one of the most common causes of morbidity and mortality, with more than ten million new cases and more than six million deaths every year worldwide. Cancer of the oral cavity which may occurs in any part of the mouth or throat. Is spreads locally involving perioral structures and metastasizes to local regional lymph nodes. Is curable if discovered early. Oral cancer may occurs on the lips or anywhere within mouth like tongue floor of mouth buckle mucosa hard and soft palate pharyngeal walls and tonsils. ${ }^{1}$ The annual estimated incidence is approximately 300,000 oral cancers; the developing nations have been reported to have more incidence of oral cancer when compared to the developed nations of which India, South America and Oceania are mostly affected. ${ }^{1}$ The most common type of oral cancer is squamous cell carcinoma causing $90 \%$ of oral cancer. Oral cancer is the most common leading cause of death across the globe, especially in the developing world. Men are affected 2 to 3 time as often as women largely due to higher use of alcohol and tobacco and poor oral hygiene. ${ }^{2}$

The life time risk of developing oral cancer in Europeans is estimated at $1.85 \%$ for men and $0.37 \%$ for women. The incidence rates are higher in Western Europe compared with Northern or southern Europe. Highest mortality rates, however, are reported from Eastern Europe. ${ }^{3}$ Within the EU countries the highest male incidence rates are found in France and Hungary, and the lowest rates are found in Greece and Cyprus. Black RJ et al., ${ }^{4}$ report the rate for oral cancer in men in France was almost seven times greater than that for men in Greece. ${ }^{4}$ The prevalence of oral cancer is high in Asian countries especially Southeast Asia ${ }^{5}$. Asians have distinct cultural practices such as betel-quid chewing as well as, varying patterns of use of tobacco and alcohol which are important risk factors that predispose to cancer of oral cavity.

\section{Tobacco products}

Tobacco being an independent risk factor, the relative risk of occurrence of oral cancer in tobacco users is 11 times that of people who never used tobacco. ${ }^{6}$ More than $90 \%$ of oral cancer cases report using tobacco products. It is used in smoking as well as smokeless forms.
Smoking includes use of cigarettes, bidi, and hookah. ${ }^{6}$ Tobacco habits other than smoking; betel-quid and areca-nut chewing; and some related nitrosamines, concluded that "there is sufficient evidence that the use of smokeless tobacco can cause oral cancer in humans and that chewing tobacco may increase the risk for oral cancer development".

The term smokeless tobacco (ST) is used in different forms in different parts of the world to describe the habitual use of unburned tobacco products in the oral cavity. There are two types of smokeless tobacco; chewing tobacco and snuff. Chewing tobacco in the form of loose leaf and snuff for oral application called Shamma. ${ }^{7}$ Shamma is a preparation of smokeless tobacco, being a mixture of powdered tobacco, carbonate of lime, ash, black pepper, oils and flavoring. ${ }^{8}$ Shamma is placed in the mouth as a quid. The location of shamma in the oral cavity has been reported as being: retained in the buccal cavity (1); kept in the vestibule of the mouth (2); allowed to rest in the gingivobuccal sulcus (3); placed in the lower labial or buccal vestibules. ${ }^{8}$ Although it is banned by governmental regulation in some countries, ST for oral use is manufactured and consumed on all continents under various names including betel-quid, chimo, gudhaku, gutkha, gul, khiwam, kahaini, maras, maras powder, mishri, nass, naswar, plug, shamma, toombaak, moist snuff. ${ }^{9}$

There are at least 30 carcinogens in ST products used globally. These products have been associated with increased risk of developing precancerous and cancerous lesions of the oral cavity, nasal cavity, and sinuses, and most commonly, squamous cell carcinoma. ${ }^{10}$ There is a relationship between the factors smokeless tobacco product (shamma), frequency of oral cancer and cancers of head and neck reported in Ethiopia, Somalia, and the Kingdom of Saudi Arabia (KSA). ${ }^{10}$ Also high prevalence of oral cancer and other oral lesions was similarly reported among shammah users in Yemen. ${ }^{11,12}$

\section{Smokeless tobacco and khat}

Khat chewing is a widespread practice in Yemen, Somalia and Ethiopia. Khat is a plant whose leaves are chewed for its stimulant effect (Cigarette smoking and shamma (smokeless chewing tobacco) are used along with Khat in Yemen., ${ }^{7,12}$ Oral squamous cell carcinoma may be linked to the synergistic effect of khat chewing and other 
known carcinogens such as polycyclic aromatic hydrocarbons and nitrosamines such as 4-(N-methyl-N-nitrosamino)-1-(3-pyridyl)1-butanone, 4-(N-methyl-N-nitrosamino)-4-(3-pyridyl)-1-butanal. About $60 \%$ of those with oral cancer were chewers. ${ }^{13}$ Since most of the Khat chewers also chewed tobacco or smoked and consumed alcohol it was not possible to separate the effect of Khat chewing and other known risk factors in development of oral cancer.

\section{Chewing of tobacco with betel quid}

It was estimated that a betel quid-chewing patient consumes 310,000 pieces of betel quid and a smoking patient consumes 14,000 packs of cigarettes before the diagnosis of oral cavity cancer on average. Besides, betel quid chewer and cigarette smoker were more prone to be diagnosed, with oral cavity cancer at a younger age than abstainers. ${ }^{12,14}$

Quid chewing is an ancient ethnic practice in Southeast Asian countries. Betel quid is chewed owing to its medicinal properties and as a symbol of social life. ${ }^{15}$ It is estimated that 600 million people use betel nut globally. The habit of betel quid chewing is widespread and its use has been documented from the East African coast to Eastern Melanesia and throughout India and South East Asia. The belief that betel quid chewing originated in an area of West Malaysia. Betel chewing probably spread to Southern India in a period of trade and early missionary activity following the Indian colonization of the Malay area and South East Asia. Additional use of tobacco and other spices are dependent on individual's choice. ${ }^{16}$ Quid chewing has been found to be an independent risk factor for oral cancer. The causal link between chewing quid without tobacco and carcinogenesis has been recognized. ${ }^{17}$ Areca nut used in betel quid is known to cause oral cancer due the presence of arecoline specific nitrosamines that are carcinogenic. ${ }^{18,19}$ Lime, a constituent of quid, acts as a tumour promoter by hydrolysing alkaloids present in the areca nut to cytotoxic and mutagenic compounds. ${ }^{18}$ Chewing of tobacco with BQ results in high exposure to carcinogenic tobacco-specific nitrosamines (TSNAs), to $\sim 1000 \mathrm{mg} /$ day. $^{20,21}$

\section{Survival}

The survival rate reported in oral cancer patients is the lowest when compared to the other major cancers such as the cancer of breast, skin, testis, prostate, uterus and urinary bladder. The number of new cases of oral cavity and pharynx cancer was 11.1 per 100,000 men and women per year. The number of deaths was 2.4 per 100,000 men and women per year. The five year survival rates for oral cancers diagnosed early is $75 \%$ compared to $20 \%$ for cancers diagnosed late. ${ }^{22}$

\section{Conclusion}

Oral cancer is the sixth most common cancer worldwide and remain the lethal disease for over $50 \%$ of cases diagnosed annually. The recognition of relevant risk factors for oral cancer can help physician to identify those patients at greater risk of developing oral cancer. Tobacco consumption and betel quid chewing are well established risk factor for development of oral cancer. It is related to dose and consuming habits. Prevention programme is urgently warranted and education should be emphasized in the public.

\section{Acknowledgments}

None.

\section{Conflicts of interest}

Authors declare there are no conflicts of interest.

\section{References}

1. Warnalulasuriya S. Global epidemiology of oral and oropharyngeal cancer. Oral Oncol. 2009;45(4-5):309-316.

2. Gupta MC. A textbook of preventive \& social medicine. 3rd ed. Jaypee Brothers: India; 2003. 624-625 p.

3. Boyle P, Ferlay J. Cancer incidence and mortality in Europe 2004. Ann oncol. 2005;16(3):481-488.

4. Black R. J, Bray F, Ferlay J, et al. Cancer incidence and mortality in the European union: cancer registry data and estimates of national incidence for 1990. Eur J Cancer. 1997;33(7):1075-1077.

5. Reichart PA, Way TH. Oral cancer, pre-cancer in Myanmar: a short review. J Oral Pathol Med. 2006;35(4):193-196.

6. Madani AH, Jahromi AS, Dikshit M, et al. Risk assessment of tobacco types, oral cancer. Am J Pharmacol Toxicol. 2010;5(1):9-13.

7. Pindborg JJ, Murti PR, Bhonsle RB, et al. Global aspects of tobacco use and its implications for oral health. Control of Tobacco-related Cancers and Other Diseases, Oxford University Press: USA; 1992. 13-23 p.

8. SAMHSA. Results from the 2005 National Survey on Drug Use and Health: National Findings; 2006.

9. Gupta PC, Ray CS. Smokeless tobacco and health in India and South Asia. Respirology. 2003;8(4):419-431.

10. Allard WF, DeVol EB, Te OB. Smokeless tobacco (shamma) and oral cancer in Saudi Arabia. Community Dent Oral Epidemiol. 1999;27(6):398-405.

11. Abdul-Hamid G, Saeed NM, Al-Kahiry W, et al. Pattern of head and neck cancer in Yemen. Gulf J Oncolog. 2010;7:21-24.

12. Scheifele C, Nassar A, Reichart PA. Prevalence of oral cancer and potentially malignant lesions among shammah users in Yemen. Oral Oncol. 2007;43(1):42-50.

13. Sawair FA1, Al-Mutwakel A, Al-Eryani K, et al. High relative frequency of oral squamous cell carcinoma in Yemen: qat, tobacco chewing as its aetiological background. Int J Environ Health Res. 2007;17(3):185-195.

14. Tsai KY, Su CC, Lin YY, et al. Quantification of betel quid chewing and cigarette smoking in oral cancer patients. Community Dent Oral Epidemiol. 2009;37(6):555- 561.

15. Raghavan V, Baruah HK. Arecanut: India's popular pasticatory history, chemistry, utilization. Econ Bot. 1958;12:315-345.

16. Mack T. The new pan-Asian paan problem. Lancet. 2001;357(9269):1638-1639.

17. Merchant A, Husain SSM, Hosain M, et al. Paan without tobacco: an independent risk factor for oral cancer. Int J Cancer. 2000;86(1):128-131.

18. Shah G, Chaturvedi P, Vaishampayan S. Areca nut as an emerging etiology of oral cancers in India. Indian $J$ Med Paediatr Oncol. 2012;33(2):71-79.

19. Warnakulasuriya S, Trivedy C, Peters TJ. Areca nut use: an independent risk factor for oral cancer. $B M J .2002 ; 324(7341): 799-800$.

20. Nair J, Nair UJ, Ohshima H, et al. Endogenous nitrosation in the oral cavity of chewers while chewing betel quid with or without tobacco. IARC Scientific Publications. 1987;84:465-469.

21. Kim M, Shin K, Baek J, et al. HPV-16, tobacco specific N-nitrosamine, and N-methyl-N'-nitro-N-nitrosguanidine in oral Carcinogenesis. Cancer Research. 1993;53(20):4811-4816.

22. Pisani P, Parkin DM, Bray F, et al. Estimates of the worldwide mortality from 25 cancers in 1990. Int J Cancer. 1999;83(1):870-873. 